\title{
Karnofsky Performance Status 10
}

National Cancer Institute

\section{Source}

National Cancer Institute. Karnofsky Performance Status 10. NCI Thesaurus. Code C105718.

Moribund; fatal processes progressing rapidly. 